\title{
Research on the Application of Regional Cultural Visual Language in the Packaging Design of Local Specialties
}

\author{
Qinlai Shen ${ }^{1, *}$
}

${ }^{1}$ Wuhan Textile University, Wuhan, Hubei, China
${ }^{*}$ Corresponding author. Email: 729103507@ qq.com

\begin{abstract}
Research content: This paper analyzes and refines the visual language of the regional culture, and explores the form and characteristics of the regional cultural visual language in the packaging design of local specialties, combined with the development trend and aesthetic requirements of modern design, and gives unique personality and aesthetic value to the packaging design of local specialties. Research method: This paper analyzes the application value of regional culture in the packaging design of local specialties, and combines the development trend of modern design and the aesthetic needs of the public, to refine and integrate the graphics, colors, text and structure that the regional culture can show. Then, this paper also analyzes the existing characteristics of the local product packaging design, so as to summarize the application value and significance of the regional cultural visual language in the local specialty packaging design. Research conclusion: The paper visually presents the regional culture and combines visual language with packaging design to give local specialty packaging design a strong cultural heritage, and shapes the individual characteristics of the current local specialty packaging design. Products that meet the aesthetic needs of mass consumers can help increase consumers' desire to buy. The application of regional cultural visual language in the packaging design of local specialties can not only promote the spread of regional culture, but also have a certain auxiliary role in promoting local economic development.
\end{abstract}

Keywords: regional culture, visual language, local specialty, packaging design

\section{INTRODUCTION}

For a region, regional culture is an important foundation for its inheritance and development. Compared with political and economic development, regional culture has more uniqueness, rich content and stable factors. To put it simply, regional culture reflects the unique customs, cultural connotations and value orientations of a place. Its existence has a certain historical heritage and allusions. Regional culture is influenced by local humanities and environment and has rich characteristics. The regional culture embodied in different regions has different connotations. It is formed by combining the long history of local development. Also because of the existence of regional culture, it gives people the feeling of homesickness. Like many cultural elements, regional culture is not a concrete existence, but it can shape the existence of regional culture in people's hearts through certain things, stories, graphics, and words.

With the introduction of the national cultural confidence policy, local industries are gradually transforming into an industrial model with cultural characteristics. The tourism industry is the mainstay. It is necessary to gradually develop cultural and creative tourism, cultural experience, etc., from measures such as the transformation of scenic spots and route optimization that promoted tourism development in the past. Local specialties have also become an effective carrier for the spread of regional culture. However, although the scenic spots have been effectively transformed, they have not been exempt. Most of the local specialties on the market have simple packaging forms and similar designs, and fail to make effective use of local cultural elements for design creation, thus being unable to arouse tourists' desire to buy and greatly restricting the effective dissemination of regional culture and the promotion and sales of local specialties. Therefore, creating a local specialty packaging full of regional cultural characteristics is of great significance to the development of the local specialty industry for the spread of local culture. Looking at the current literature research on regional culture on packaging design, in 2019, Hu Bing analyzed the current situation and mentioned many problems in the packaging design of local products in the article "Application of Local Cultural Symbols in Packaging Design of Native Products" published on "Art . Theory". He put forward the design concept of "people- 
oriented, region-oriented", and analyzed the application of local culture in the packaging design of native products from two aspects: spiritual culture and material culture. In the same year, the article "Regional Cultural Inheritance in the Design of Local Specialty Packaging" Zhao Juyu published on "Packaging Engineering", once again analyzed the basic characteristics of regional culture applied to local specialty packaging design, and the cultural and economic value of local specialty packaging. It is concluded that spreading regional culture with the help of local specialty packaging will help promote regional economic development and enhance regional competitiveness.

Based on the previous research, this paper analyzes the application value of regional culture in the packaging of local specialties, focuses on analyzing the visual elements of regional culture, digs out the application methods and value of regional cultural visual language, and tries to creatively use regional cultural visual elements to lay a theoretical support for the application value of regional cultural visual language in local specialty packaging design.

\section{STATUS QUO ANALYSIS OF PACKAGING DESIGN OF LOCAL SPECIALTIES}

For most consumers, the way to get in touch with local specialties is mainly through tourism and local crop shopping markets. In a certain sense, what the local specialties leave behind is something with a rural atmosphere, and even they pay too much attention to the value of the local specialties but ignore the existence of the packaging, so there will not be too much attention to the packaging of the local specialties.

\section{A. Homogenization of packaging design}

In the current society with convenient transportation, open market, and cultural tolerance, local specialties are relatively no longer affected and restricted by regions. People can buy special products from the north in the south, and the can also buy special products from the south in the north. As a result, many local specialties do not necessarily belong to the place where it appears, so its packaging is particularly important. However, for many local specialties, they do not realize the importance of their packaging. There are many flaws in the packaging form. Many designs are simply packaged with a few rough words and photos of the product. Taking the "Muchuishu" that appears in major tourist attractions as an example, as one of the three major specialty products in Phoenix District, Xiangxi, it has been circulated among the people for more than two hundred years since the Qing Dynasty. It is deeply loved by people for its soft, crisp, fragrant and refreshing taste. However, because there is no unified packaging form to form a brand responsive to it, the historical background and even its original birthplace of Muchuishu are not well known to the world. Not only did it fail to spread the culture of Xiangxi, it also reduced the product's value grade.

\section{B. Lack of regional cultural characteristics}

As a local specialty, its formation is closely related to the local natural environment and humanistic environment. However, as the product's business model is shaped, in the process of market circulation, its commercial value gradually replaces the product's own humanistic and regional characteristics. The packaging form is also polarized, either being particularly simple and crude, or being over-packed to make the product value for money. As far as the packaging of tea and moon cakes is concerned, the origin of tea should have local cultural heritage, but the packaging of tea is too exquisite and gorgeous, making the popular tea into a luxury item. Even when it comes to tea, what comes to mind is not the function of tea, but its social value. The same is true for moon cakes. Moon cakes are supposed to be a carrier of Mid-Autumn Festival blessings. However, the variety of moon cake packaging on the market makes moon cakes, which should be full of traditional Chinese festival cultural features, also a tool of commercial pastime.

\section{Lack of innovation in packaging design approaches}

For the packaging design of local specialties, the designer's ideas play an important role in the entire design process. The designer's thinking is imprisoned and has a certain influence on the current situation of local specialty packaging design. In the current social background of economic development, support for local industries is gradually increasing. Local specialties as a carrier to develop the local industrial economy and drive the income of local industries, if packaging designers do not form the brand awareness and innovation ability to promote the development of regional culture when designing their product packaging, they will make the local specialty packaging design out of the influence of regional culture, so that the product packaging designed will not only fail to highlight the regional culture, let alone establish a brand marketing model with memory points.

\section{THE VALUE OF LOCAL SPECIALTY PACKAGING DESIGN}

In the process of promoting local specialties, whether it is to promote the local specialties themselves or the cultural connotation behind them, packaging is needed to resonate with consumers. Therefore, to create a local specialty packaging with regional cultural characteristics, it is necessary to conduct research on the value that can be expressed. 


\section{A. Enhancing visual beauty and catering to the public's aesthetics}

Modern design has undergone changes again and again, and people's aesthetic requirements for design have gradually increased. Coupled with the development of Internet technology, the requirements of social groups for product packaging are not only the carrier of a product, but also the emotional experience that the packaging can bring. Therefore, when designing the packaging of local specialties, by analyzing the cultural characteristics of the local area, it can be transformed visually. It is not only necessary to give people a cultural visual experience, but also to cater to the aesthetic needs of the current public. Only in this way can it be more easily accepted. The gift box packaging designed by the famous packaging designer Pan $\mathrm{Hu}$ for BESTORE uses the packaging shape to trace the court gift box to carry on a kind of cultural inheritance. The illustration graphics cater to the design trend. The works are not only aesthetic, but also in line with or even beyond popular taste.

\section{B. Giving cultural connotation and increasing personality characteristics}

There are undoubtedly two ways to create the cultural value of packaging design: one is to analyze and take example by the regional culture, and the other is to inherit and innovate the traditional culture. From the perspective of regional culture, different regions have their own characteristics in behavior habits, language communication, aesthetic orientation, etc. due to different historical backgrounds, social environments and other factors. It is precisely because of this that a unique and colorful regional culture has been formed. Creating different cultural moods through rich regional text content and graphic colors, and giving the connotation of regional culture to the packaging design of local products, can not only help people understand and trace regional culture through packaging, but also help to enhance the brand value and market circulation of products. Analyzing from the perspective of traditional culture, the traditional culture handed down in each region will inevitably have intersections with the local specialties rich in this region in a certain time or space dimension. Therefore, the reproduction of traditional culture in packaging design is also a kind of development of traditional culture.

\section{Improving market recognition and consolidating economic value}

As the saying goes, "People rely on clothes, horses rely on saddles." For any product, from production to market sales, packaging is very important. In addition to protecting the product, it must also enhance its added value. When similar products are displayed, it can make the products be noticed for the first sight. Especially for local specialties, the integration of regional culture into the packaging design, as an opportunity to trigger people's emotional resonance with the regional culture, helps to enhance consumers' trust and recognition of the product. The packaging of Shanghai old wine uses Shikumen with strong Shanghai characteristics as a design element to collide with the emotional appeal of Shanghai people, achieving a good sense of identity, and promoting product sales.

\section{SHAPING THE VISUAL LANGUAGE OF REGIONAL CULTURE}

For packaging design, visual elements are mainly composed of graphics, colors, text, and structure. By analyzing the characteristics of regional culture and creating with the aid of visual elements, it has a visually effective impact on product packaging, and brings strong sensory feelings to consumers, thereby triggering curiosity to promote consumption.

\section{A. Presentation of visual elements}

As the most important form of expression in packaging design, graphics are transformed by different regional cultures, and the connotations they give to graphics are also different. Graphic elements in regional culture not only exist in traditional folk art, but can also be art forms such as architectural styles or historical and cultural allusions. Through in-depth exploration of the graphic elements of regional culture, absorbing the expression methods of traditional folk art, combined with modern art design concepts, the regional culture is presented on the packaging in the form of graphics, which not only brings a cordial feeling to consumers and promotes China's excellent traditional culture, but also gives products a unique personality and promotes

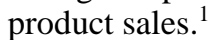

In different regional cultures, the psychological feelings that color brings to people will be different. When the designers refine the color language of the regional culture, they must deeply dig into the connotation of the regional culture and use its color language to shape the cultural mood of the product. By combining packaging design with color language, they need to give packaging a deeper concept of regional culture, which helps to meet the psychological needs of consumers. For example, the "Ying Kee Tea House" designed by Chen Youjian uses traditional Chinese red and black to match the Chinese "Zhou Yi", giving the packaging a strong Chinese style.

Chinese characters with a history of more than 8,000 years are extensive and profound. People usually think that characters are only used to convey a kind of information. However, for packaging design, characters are more of a rhythm of Chinese character culture.

Ling Shiyi, Fusion and Innovation of Regional Cultura Visual Language in Packaging Design [J]. Designs, 2020, 3. 
Taking calligraphy fonts as the mainstay, and presenting the text in the packaging design, it can give the packaging a certain degree of artistry, while also conveying a strong Chinese regional cultural characteristic. Taking the Shanghai specialty "Spiced Beans" as an example, the calligraphy "老城隍庙 (Old Temple of Town God)" is located in the eye-catching position of the package, which is to give the product a rich regional color with the calligraphy with strong regional characteristics, having a good promotion effect.

\section{B. Expression of structural image}

The use of material and structure is also an important way for the packaging design of local specialties. The specific expression is that the designer creates a unique packaging shape based on the characteristics of different local specialties and combining local cultural characteristics. While highlighting its own unique shape, it is a must to pay attention to the portability of packaging design, ergonomics and humanized design. And its shape design must be tasteful, so as to bring consumers a novel feeling, attract consumers' attention, and stimulate consumers' desire to buy. Of course, this type of packaging design may have the difficulty that it cannot be mass-produced, but it is undeniable that its application to the packaging of local specialties will help the spread of regional culture and the promotion of local specialties. For example, the packaging of "Jiugui Liquor" designed by Huang Yongsheng, cleverly used the linen cloth and earthenware materials of Xiangxi folk custom to shape the bottle body. The overall design fits the brand positioning, creates a brand personality derived from nature, and brings consumers a simple and elegant visual effect.

\section{CONCLUSION}

The development of economic globalization has gradually matured, and the policy of cultural selfconfidence has been deeply rooted in the hearts of the people. Therefore, inheriting regional culture and spreading cultural characteristics have important social values and significance. It is necessary to use the packaging design of local specialties to explore the cultural elements with beautiful colors in the regional culture and present them visually through artistic design techniques. It is also necessary to combine modern aesthetics to create a visual language with distinctive regional characteristics, profound cultural heritage, unique aesthetic expression and strong characteristics of the times, to give local specialty packaging a strong sense of public identity, and to continuously innovate and develop new packaging forms. It will also be a must to inherit and carry forward Chinese excellent regional culture with the help of packaging design, so as to achieve the purpose of integrating regional culture and modern packaging design.

\section{References}

[1] Zhao Rong, The Visual Language and Design Strategy of Huxiang Cultural Characteristic Agricultural Product Packaging Against the Background of Precise Poverty Alleviation [J] Southern Forum, 2020(4): 29-30. (in Chinese)

[2] Ling Shiyi, Fusion and Innovation of Regional Cultural Visua Language in Packaging Design [J]. Designs, 2020(3): 78-80. (in Chinese)

[3] Li Ming, Research on the High Efficiency Application of Visual Graphic Elements in Agricultural Products Packaging [J] Packaging Engineering, 2020(3). (in Chinese)

[4] Zhang Kangning, Packaging Design of Agricultural Products [J]. Packaging Engineering, 2020(3). (in Chinese)

[5] Hu Bing, Application of Local Cultural Symbols in Packaging Design of Native Products [J]. Art Theory, 2019(12): 39-41. (in Chinese)

[6] Zhao Juyu, Regional Cultural Inheritance in the Design of Local Specialty Packaging [J]. Packaging Engineering, 2019(8): 298301. (in Chinese)

[7] He Xiangwen, Analysis on the Design Route Map of the Application of Regional Culture Elements in the Packaging Design of Native Products [J]. Designs, 2017(3): 98-99. (in Chinese)

[8] Ye Zhi, Zhang Lingling, Innovation and Performance of Chinese Traditional Element Visual Symbols in Modern Design [J]. Art Panorama, 2016(3): 133. (in Chinese) 